\title{
Postpartum Obesity in Cuba: Risk Outweighs Response
}

\author{
Calixto Orozco-Muñoz MD MPH, Oscar Cañizares-Luna MD MS PhD, Nélida L. Sarasa-Muñoz MD MS PhD
}

In the last 20 years obesity has emerged as one of the top causes of preventable deaths worldwide and is a health problem for adult women globally; according to $\mathrm{WHO}$, in $2014,40 \%$ were overweight and $15 \%$ obese.[1]

Pregnancy brings risk for excessive weight gain and can result in short-, medium- or long-term postpartum weight retention. In some women, the result is obesity. Excessive weight gain during pregnancy is a powerful risk factor for new and persistent obesity. What's more, women who have given birth once or twice are three to four times more likely to become obese in the five years following childbirth than women who have had no children during the same period.[2]

The first gestational weight-gain standards were issued globally and in Cuba in 1990. They were designed to prevent premature births and low birthweight in newborns. Nevertheless, rising rates of obesity and overweight in early pregnancy continued, spurring a reorientation toward a more comprehensive approach designed to protect overall maternal health, promote maintenance of prepregnancy weight, and prevent childhood obesity, making weight monitoring in pregnancy even more important.[3] To this end, Cuba began applying national nutritional assessment standards for pregnant women in 2010, based on guidelines issued by the US National Institutes of Health.

In Cuba, weight gain is monitored systematically with reference to prepregnancy body mass index (BMI). Once a woman's pregnancy is confirmed, her weight is followed closely to prevent fluctuations that portend possible complications for her or her newborn. However, we believe there are still gaps to be closed to increase effectiveness of these strategies, particularly in primary health care, since:

- BMI alone does not provide the information necessary to assess prepregnancy nutrition and weight gain, and should be complemented by other indicators including hip and waist circumference.

- Some pregnant women have low risk perception-even when they have sufficient information-and do not follow their doctors' recommendations, putting on more weight than they should.

- Not all women return to their pre-pregnancy weight within a year, whether because they augment their diet to produce enough quality breast milk or become pregnant again, or for other reasons. This can lead to even more weight gain.

Despite systematic and regularly scheduled clinical exams, anthropometric measurements, bloodwork, ultrasounds and genetic studies, the excess weight gain during pregnancy that we found (78\% were overweight, and $77.1 \%$ obese)[4] and its relation to postpartum weight retention leads us to conclude that more needs to be done. And perhaps done differently.

Too much emphasis is placed on biological determinants with little creativity on the part of the primary care team to develop proactive, health-promoting strategies by individuals, families, and communities to effectively support lifestyle changes before, during and after pregnancy.

It's not a question of needing more biomedical research, but rather broadening health strategies to include social determinants. Obesity is a multifactoral health issue and the approach should include attention to lifestyle, environment and organization of health services, among other determinants.

Biological exams alone cannot provide the full picture. For example, they don't reveal how metabolic reactions affect alterations in organ tissue, nor do they explain psychological, cultural or socioeconomic factors that work for or against a woman's health. In essence, we are talking about biological phenomena that are socially conditioned, reflected in concrete lifestyles. Modifying habits before, during, and after childbirth with systematic, personalized exercise regimens, a healthy diet and actions directed at improving mental health can positively affect lipid and protein metabolism and reduce risk of obesity and overweight.

\section{We propose a more comprehensive assessment that includes socioeconomic and cardiometabolic variables}

We propose a more comprehensive assessment that includes socioeconomic and cardiometabolic variable. This implies incorporating empirical research methods and the social sciences into regular medical practice - including, along with clinical examination, physical somatometry; chemical, epidemiologic and statistical analyses; and applicable diagnostic technologies. Using a broader range of tools will help modify concepts related to gestational weight gain, enrich scientific theory and promote new tools to improve health monitoring during pregnancy. This would have benefits for professional development of primary care givers, and the health of mothers and their newborns.

We understand that our proposal may fly in the face of traditional research methodology in primary care, by suggesting a different perspective with social sciences as a point of departure. We believe a more multidisciplinary, cross-sectoral strategy is called for to address complex women's health issues and to truly implement an integrated bio-psychosocial approach. -1 .

1. World Health Organization [Internet]. Geneva: World Health Organization; 2016. Media Center. Obesity and Overweight Data 2016; 2016 Jun [cited 2016 Nov 24]; [about 3 screens]. Available from: www.who.int/mediacentre/ factsheets/fs311/en/

2. Herring SJ, Rose MZ, Skouteris H, Oken E. Optimizing weight gain in pregnancy to prevent obesity in women and children. Diabetes Obes Metab [Internet]. 2012 Mar [cited 2016 Nov 24];14(3):195-203. Available from: http:// onlinelibrary.wiley.com/doi/ 10.1111/j.1463-1326.2011.01489.x/full

3. Restall A, Taylor RS, Thompson JM, Flower D, Dekker GA, Kenny LC, et al. Risk factors for excessive gestational weight gain in a healthy, nulliparous cohort. J Obes [Internet]. 2014 [cited 2016 Nov 24];2014:148391. Available from: https://www.ncbi.nlm.nih.gov/pmc/articles/pmid/24995130/

4. Sarasa Muñoz NL, Hernández Díaz D, Lima Pérez Y. Ganancias ponderales del embarazo: una doble amenaza al futuro. Proceedings of the I Jornada Virtual de Doctores en Ciencias, 2015 Oct 1-31; University of Medical Sciences of Havana, Havana, Cuba. Havana: Medical University of Havana; 2015. 9 p. Spanish.

Submitted: January 27, 2017

Approved for publication: February 25, 2017

Disclosures: None

Correspondence: calixtoom@infomed.s/d.cu 